\title{
Grammatical and pragmatic properties of the DP in children with Specific Language Impairment (SLI) and in children with High Functioning Autism (HFA)
}

\author{
Ava Creemers and Jeannette Schaeffer \\ University of Pennsylvania / Universiteit van Amsterdam
}

\begin{abstract}
This study investigates whether grammar and pragmatics are separate linguistic components or not, and whether children with SLI and children with HFA have overlapping or distinct linguistic profiles. We examine two DP-related phenomena: the mass-count distinction (grammatical) and the choice for a definite/ indefinite article (pragmatic). We tested 27 children with HFA aged 6-14, age and gender matched to 27 children with SLI, and 27 TD controls on a Quantity Judgment Task (mass-count) and an Elicited Production Task (article choice). Our results show that pragmatics can be impaired independently from grammar (in HFA) and vice versa (in SLI), providing evidence for a modular view of grammar and pragmatics, and against an overlap in the profiles of SLI and HFA.
\end{abstract}

Keywords: Autism, Specific Language Impairment, mass-count, article choice, domain-specificity, double dissociation

\section{Introduction}

An important debate in different domains of science concerns the relationship between Autism Spectrum Disorder (ASD) and Specific Language Impairment (SLI). The traditional view is that ASD and SLI are two unrelated disorders with distinct etiologies: individuals diagnosed with SLI show severe grammatical impairments, with mostly intact pragmatics (Friedmann \& Novogrodsky 2008; 2011; van der Lely 1998), while children with autism, for whom pragmatic problems are argued to be the primary deficit, show mostly intact grammar (see Baron-Cohen 1988; Frith 1989; and Tager-Flusberg 1989 for reviews). 
More recently, researchers have proposed an overlap in the profiles of the two conditions: it is argued that individuals with SLI do not only have an impairment specific to grammar, but that they also have problems with pragmatics that cannot be explained as secondary consequences (see for instance Bishop 2000 and Gibson et al. 2013 on Pragmatic Language Impairment (PLI) and Friedmann \& Novogrodsky 2011 on Pragmatic SLI (PraSLI)), and that the language development of individuals with ASD is deviant when compared to typically developing (TD) children (see for instance Kjelgaard \& Tager-Flusberg 2001 on variable language functioning in autism and Perovic, Modyanova \& Wexler 2013 on deviant development of Binding Principle A in a subgroup of children with ASD).

The current study contributes to this discussion by investigating a grammatical and a pragmatic phenomenon in the nominal domain in HFA and SLI: the mass-count distinction in so-called flexible nouns (some rope vs. three ropes) being a grammatical phenomenon, and the choice between a definite and indefinite article being driven by pragmatic principles. We argue that the results of this comparison provide evidence for distinct profiles of HFA and SLI.

Another on-going debate in linguistics concerns the modularity of grammar and pragmatics, and the question whether language consists of autonomous domain-specific modules that operate independently (Fodor 1983, a.o.), or whether language is non-modular in the sense that language results from non-linguistic and domain-general principles (Rumelhart \& McClelland 1982, a.o.). ${ }^{1}$ Our results suggest a double dissociation between the investigated pragmatic phenomenon and the grammatical phenomenon and thus provide evidence in favor of a modular view of pragmatics vs. grammar.

In the next section we describe the mass-count phenomenon (2.1) and the choice for a definite or indefinite article (2.2), followed by our research questions, hypotheses and predictions (2.3). Section 3 describes the methods of our masscount and article choice experiments, Section 4 presents the results, and Section 5 provides a discussion of the research questions and the conclusion.

\section{Background}

\subsection{The mass-count phenomenon}

The mass-count distinction is the grammatical distinction between nouns that can be counted (e.g. $\operatorname{dog}(s), \operatorname{car}(s)$, house(s)) and nouns that cannot be counted

1. When referring to 'grammar' we mean the structural aspect of language, i.e. morphosyntax. When referring to pragmatics, we mean the use of language in social contexts. 
(e.g. dough, sand, water). In English and Dutch, count nouns, in contrast to mass nouns, can be pluralized, may be preceded by indefinite articles, or by a cardinal numerals.

However, the mass-count distinction is not as clear-cut as presented above, as some nouns that typically get a 'volume-based' interpretation can be used in count syntax (1) and some nouns that typically receive an 'individual-item' interpretation can be used in mass syntax (2).

(1) twee biertjes

two beer-DIM-PL

'two beers'

(2) Er zit hond in de soep

There is dog in the soup (De Belder 2011)

Examples as in (1) and (2) provide one of the main pieces of evidence in favor of a syntactic analysis of the mass-count distinction. Borer (2005) argues that the mass-count distinction is not marked on the nouns themselves, but rather by their morphosyntactic context, e.g., plural inflection or the indefinite article in English, which divide stuff (mass) into countable items.

Previous research has shown that English TD children distinguish mass from count around age 4 (Barner \& Snedeker 2005). There are hardly any studies examining the acquisition of the mass-count distinction in children with autism or with SLI (but see Froud and Van der Lely 2008 for mass-count in SLI).

\subsection{Article choice}

The choice between a definite and indefinite article depends on speaker and hearer assumptions, and can thus be assumed to be driven by pragmatic principles. Definite NPs are typically associated with established discourse referents that are familiar to speaker and hearer, while indefinite NPs are used to introduce new referents in the discourse (a.o. Stalnaker 1974; 1978; Heim 1982).

(3) Ik heb vorige week een film gezien. De film was niet erg interessant 'I saw a movie last week. The movie was not very interesting'

In (3), the indefinite NP a movie is used to introduce a new entity into the discourse context, and subsequently, when that entity is introduced, it is further referred to with the definite article $d e$. In addition to the referential indefinite exemplified in (3) in which the speaker knows the referent of the noun film, the indefinite article can also be used non-referentially when neither the speaker nor the hearer knows the referent of the noun, as in (4): 
(4) Ik heb zin om een film te zien (wat voor film dan ook)

'I feel like seeing a movie' (whatever movie it is)

Acquisition studies show that the different properties of definite and indefinite articles follow different developmental paths. Firstly, many studies find that children overuse the definite article in referential indefinite contexts (Maratsos 1976; Karmiloff-Smith 1979; Schaeffer \& Matthewson 2005). Secondly, Van Hout, Harrigan \& Villiers (2010) show that pre-school TD children (aged 3;7-5;3) have difficulties comprehending the indefinite article: they are overly liberal in their interpretation of the indefinite article: the adults correctly choose a new referent $87 \%$ of the time, whereas the children choose a new referent only $41 \%$ of the time. Van Hout et al. explain this non-adultlike interpretation of indefinites by the idea that children are often insensitive to implicatures when they interpret scalar terms (Noveck 2001; Papafragou 2006; Papafragou \& Musolino 2003; Pouscoulous, Noveck, Politzer \& Bastide 2007). Similar to a scalar term such as some, which implies not all, the and $a$ provide a contrastive set in which the is the logically stronger and most informative member of the pair. Therefore, in adult speech indefinite interpretations are analyzed as implicatures that result from not using the definite article in corresponding expressions (Hawkins 1991; Horn 2006). Van Hout et al. show that children often fail to draw a scalar implicature when they interpret indefinite NPs, which results in an arbitrary choice between a determined referent meaning and a non-determined referent meaning when they hear an indefinite.

Although van Hout et al. consider the scalar implicature for definiteness only in terms of comprehension, we assume that scalar implicatures apply in production as well. In production, this predicts $a$-overuse, as some studies investigating children with SLI found, indeed. Polite, Leonard \& Roberts (2011) report that children with SLI very frequently produce the indefinite article $a$ in place of the appropriate definite article the, whereas they do not differ from age-matched TD children in the indefinite condition. Chondrogianni \& Marinis (2014) find that children with SLI produce significantly more substitutions of the definite article than the TD age-matched children (SLI: $a$-substitutions of $25 \%$, TD age-matched: $3 \%)$, but not of the indefinite article.

\subsection{Hypotheses and predictions}

We first hypothesize that grammar and pragmatics are separate linguistic components, i.e., that they can be impaired independently of each other. Following the traditional hypotheses that children with SLI are mainly impaired in their grammar, while having intact pragmatics, and, vice versa, that children with 
High-Functioning Autism are mainly impaired in their pragmatics, but have intact grammar, we make the following two predictions:

(5) For Article Choice: HFA < TD; SLI = TD

(6) For Mass Count: SLI < TD; HFA = TD

Our second hypothesis is that SLI and High-Functioning Autism are not part of the same continuum, predicting that the SLI and the High-Functioning Autism group do not perform similarly on grammar and pragmatics.

\section{Methods}

\subsection{Participants}

We recruited 27 children diagnosed with High-Functioning Autism (henceforth: HFA) by psychiatrists according to the DSM_IV (American Psychiatric Association 2000), aged 5-14 (mean 10;4, SD 2.38) and matched them on age and gender to 27 children diagnosed with SLI by speech therapists at special schools for speech and language problems (mean 10;2, SD 2.27), and 27 TD children (mean 10;4, SD 2.22). Children with SLI or HFA with an IQ $<85$ and/or officially diagnosed with any additional disorder were not included. Finally, 12 adult mother tongue speakers of Dutch aged 21-53 (mean 35;9, SD 14.37) were tested to ensure the psychological reality of the expected target responses.

As the current study is part of a much larger project, besides the mass-count and the article-choice experiments, the participants were also administered 15 other tests, including the CCC-2-NL (Geurts 2007) and the CELF-IV (Semel et al. 2008). The CCC scores confirmed the autism diagnosis of the children with HFA as opposed to the children with SLI (HFA Social Interaction Difference Index (SIDI): mean $81.6, \mathrm{SD}=19.8$; SLI SIDI: mean $=14.9, \mathrm{SD}=12.9$ ). Vice versa, the CELF percentiles underscored the grammatical impairment in the children with SLI, as opposed to the HFA group (SLI CELF: mean 7.9, SD 7.34; HFA CELF: mean 53.7, SD 29.46).

\subsection{Materials and procedure mass-count (MC)}

Using a Quantity Judgment Task with pictures (Barner and Snedeker 2005; Hacohen and Schaeffer 2013), participants are asked "Wie heeft er meer X?" ('Who has more $\mathrm{X}$ ?'), where $\mathrm{X}$ is a flexible noun appearing in either count or mass syntax. The use of these flexible nouns forces the participants to base their interpretation 
purely on morphosyntactic knowledge (the plural morpheme) rather than on conceptual knowledge. An illustration is given in (7) and (8):

(7) Count syntax: Wie heeft er meer pizza's?

'Who has more pizzas?'

Correct answer: the horseman

(8) Mass syntax: Wie heeft er meer pizza?

'Who has more pizza?'

Correct answer: the cowboy

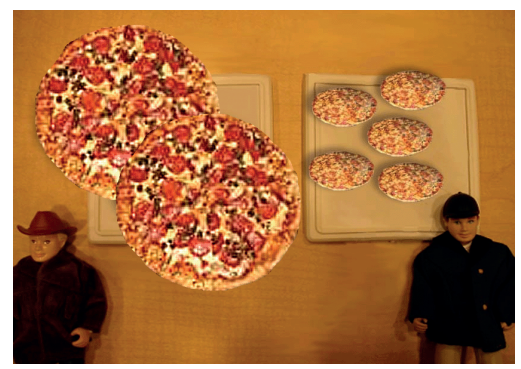

Figure 1. Test item mass-count

The test consisted of 11 items testing the mass condition, 12 items testing the count condition, and 8 fillers, presented in pseudo-randomized order. ${ }^{2}$

\subsection{Materials and procedure article choice (AC)}

AC was tested by an elicited production task in which participants are asked to describe an event in a picture or short video clip displayed on a computer screen to an experimenter who cannot see the screen, while a second experimenter is sitting next to the participant.

The test consists of 18 fillers (used for another test) and 18 experimental items equally divided over the three conditions: definite, indefinite referential, and indefinite non-referential. In the definite condition, a character is first introduced using an image and afterwards the participant is presented a short movie clip in which the character performs an action - illustrated in (9), and in Figures 2 and 3 (still of the movie clip).

(9) Definite condition

Experimenter 1: Hé, wie zie je op het plaatje?

'Hey, who do you see on the picture?'

2. One of the items in the mass condition was excluded (Wie heeft er meer papier? 'Who has more paper?') since all groups performed less well on this item as compared to the other items. 
Child: ${ }^{*}$ Naam van pop op plaatje !

${ }^{\star}$ Name of het puppet on the image ${ }^{*}$ !

Experimenter 1: En wat nog meer?

'And what else?'

Child: Een beer!

'A bear!'

[the image changes into a short movie clip in which the puppet hugs the bear]

Experimenter 1: En wat deed ${ }^{\star}$ naam ${ }^{*}$ daarnet?

'And what did * name* just do?'

Child: Hij knuffelde de/het beer.

'He hugged the bear.'

${ }^{*}$ Hij knuffelde een beer.

'He hugged a bear.'

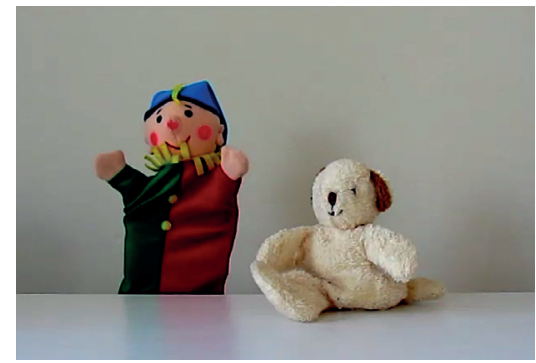

Figure 2. Definite condition (I)

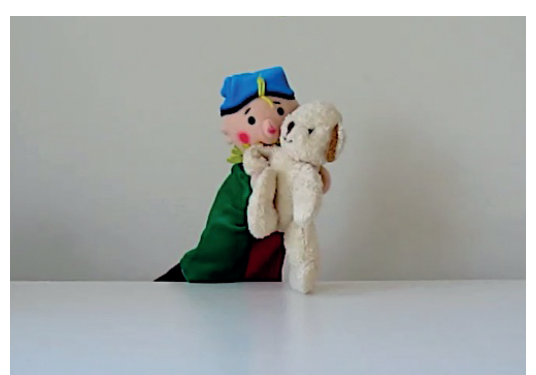

Figure 3. Definite condition (II)

The indefinite conditions use a single image and are illustrated in (10) and (11):

(10) Indefinite referential condition

Experimenter 1: Hé, wie zie je op het plaatje?

'Hey, who do you see on the picture?'

Child: Ernie!

'Ernie!'

Experimenter 1: En wat heeft Ernie net gedaan?

'And what did Ernie just do?'

Child: Hij heeft een pizza gebakken.

'He baked a pizza.'

${ }^{*}$ Hij heeft de/het pizza gebakken.

*'He baked the pizza.' 

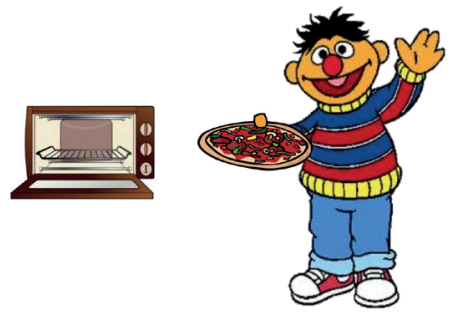

Figure 4. Indefinite referential condition

(11) Indefinite non-referential condition

Experimenter 1: Hé, wie zie je op het plaatje?

'Hey, who do you see on the picture?'

Child: Elmo!

'Elmo!'

Experimenter 1: Elmo zegt: 'Oh, ik verveel me zo, ik weet niet wat ik moet doen. Oh, weet je wat, ik ga naar de keuken, en dan ga ik daar iets bakken! 'Elmo says: 'Oh, I am so bored, I do not know what I should do. Oh, you know what, I am going to the kitchen, and then I am going to bake something!'

Experimenter 1: Wat denk je dat Elmo gaat doen in de keuken?

'What do you think Elmo is going to do in the kitchen?'

Child: Hij gaat een cake/taart/koekje bakken!

'He is going to bake a cake/pie/cookie!'

${ }^{\star}$ Hij gaat de/het cake/taart/koekje bakken!

'He is going to bake the cake/pie/cookie!'

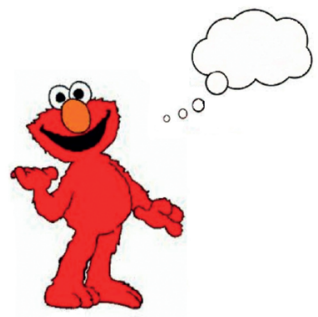

Figure 5. Indefinite non-referential condition 


\section{Results and discussion}

\subsection{Group results}

\subsubsection{Mass-count}

Figure 6 represents the accuracy scores for the four groups of participants per condition. The rightmost bars show the combined accuracy scores for the flexible mass and flexible count conditions, as a Wilcoxon Signed Ranks Test shows no significant differences between the accuracy scores on the two conditions (HFA: $p=.366, \mathrm{z}=-.904$; SLI: $p=.620, \mathrm{z}=-.495)$.

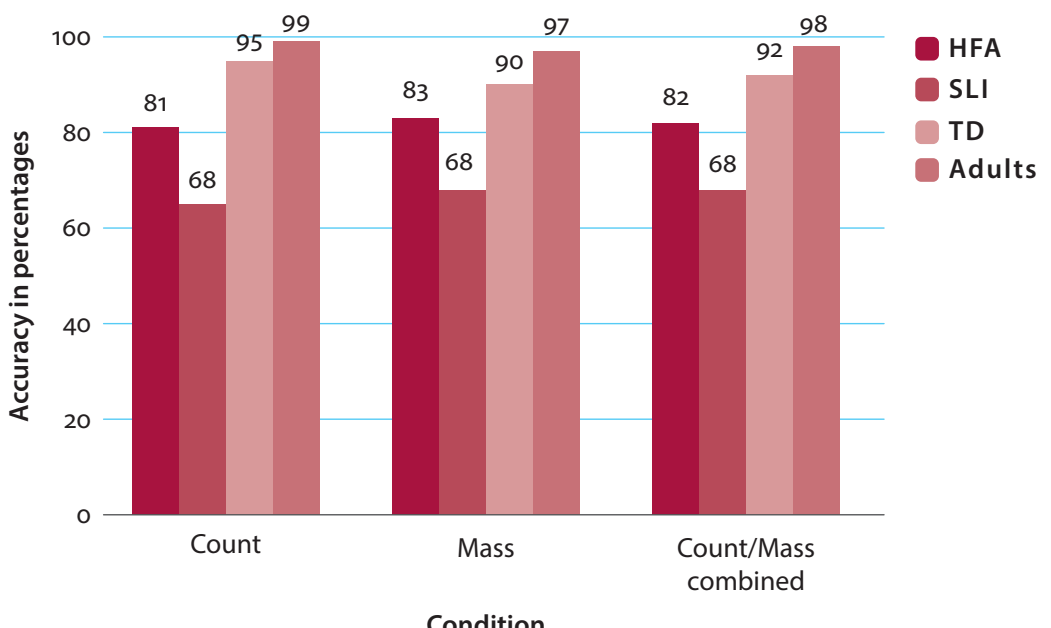

Figure 6. Mass-count: accuracy (rate of correct responses) in percentages per group

Overall, we see that all groups, even the HFA and SLI groups, are quite competent at this task. Nonetheless, a Kruskal-Wallis test reveals that there is a difference between accuracy scores of the groups $(\mathrm{H}(3)=33,732, p \leq 0.001)$. A pairwise posthoc Kruskal-Wallis test (chance-level adjusted) shows that the SLI group performs significantly worse than the TD children $(p \leq 0.001)$, while the HFA group does not $(p=0.352)$, confirming our prediction that children with SLI perform badly on grammar (in this case the mass-count distinction) and children with HFA are TDlike in this respect. The children who fail at this experiment show no sensitivity to the plural marker, suggesting a morphosyntactic or grammatical deficit.

\subsubsection{Article choice (AC)- Indefinite conditions}

Figure 8 provides the accuracy rates and the rates of substitutions on the indefinite conditions. All responses that were different from the use of the indefinite or definite article were scored as 'other'. 


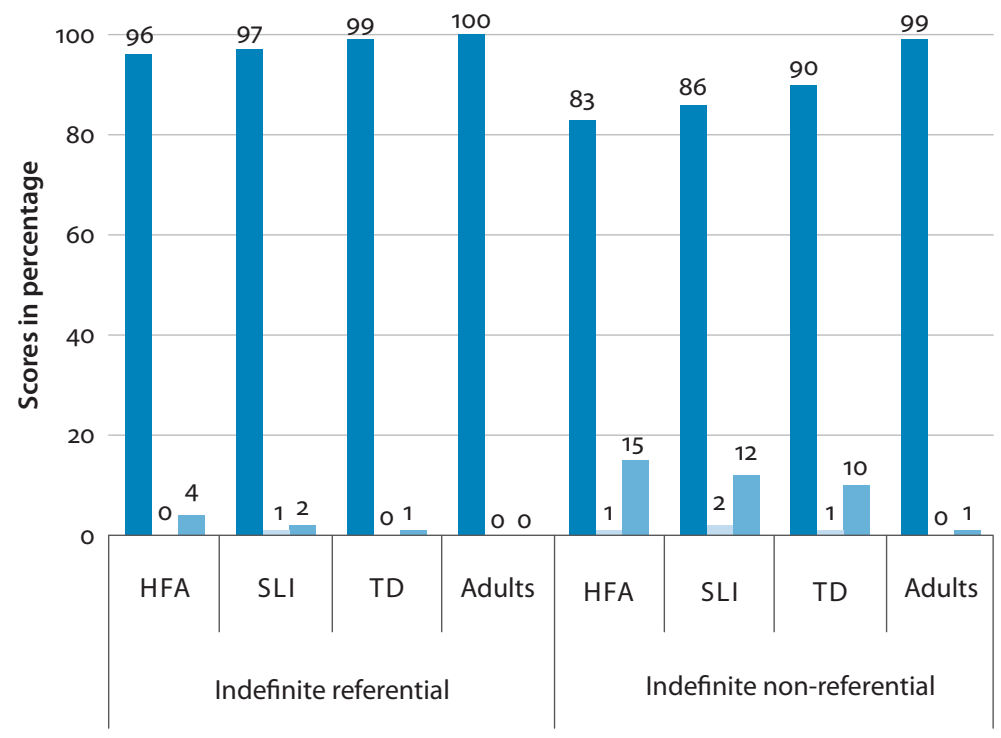

Accuracy Substitution with de/het ('the') Other

Figure 7. Proportional scores of responses in the indefinite conditions

Figure 7 shows that all participants perform well. A Kruskal-Wallis test reveals no difference between the accuracy scores of the three matched groups in both indefinite conditions (non-referential: $\mathrm{H}(3)=2.381, p=.304$, referential: $\mathrm{H}(3)=4.507$, $p=.105$ ). Moreover, we see that there are hardly any substitutions with de ('the'overuse) in the indefinite condition: between $0 \%$ and $2 \%$. These results are in line with the findings of Polite et al. (2011) and Chondrogianni \& Marinis (2014) for the SLI groups they investigated.

\subsubsection{Article Choice - Definite condition}

Figure 8 provides the accuracy rates, the rates of substitution with een ('a'), and the amount of 'other' responses in the definite condition.

These results demonstrate that the adults and the TD group have ceiling accuracies, while the SLI and HFA groups both have a mean accuracy of $81 \%$. Although we cannot say that the SLI and HFA groups performed particularly badly on the definite condition, a Kruskal-Wallis test does show that the accuracy scores of the three matched groups are significantly different $(\mathrm{H}(3)=8.676, p=.013)$. A pairwise post-hoc Kruskal-Wallis test (chance-level adjusted) reveals that the TD group outperforms not only the HFA group $(p=.047)$, but also the SLI group $(p=.023)$.

Figure 8 further shows that substitution rates in the TD group are $4 \%$, while they are $13 \%$ for the children with SLI and 15\% for the children with HFA. These percentages of een-overuse are significantly different from the percentages 


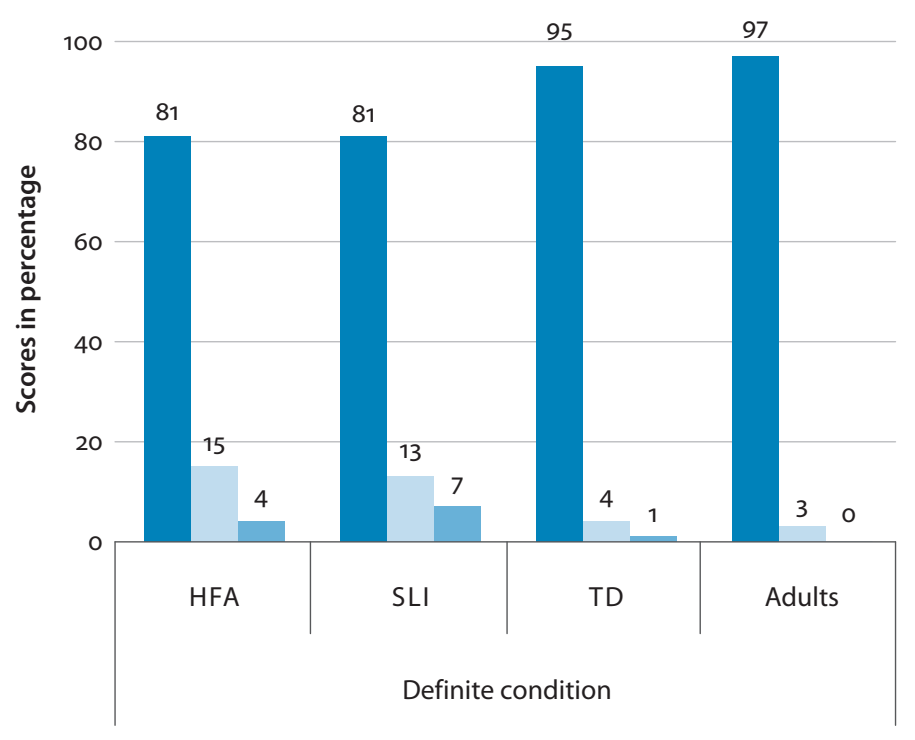

Accuracy Substitution with een ('a')

Other

Figure 8. Proportional scores of responses in the definite condition

of $d e$-overuse in the HFA group $\left(\chi^{2}(2)=16.294, p<.001\right)$ and in the SLI group $\left(\chi^{2}(2)=14.973, p=.001\right)$, but not in the TD group $\left(\chi^{2}(2)=5.200, p=.074\right)$. Post hoc analysis with Wilcoxon signed-rank tests (applied with a Bonferroni correction, resulting in $\alpha=0.017$ ) shows that in the SLI as well as the HFA group there are significantly more substitutions in the definite condition than in both indefinite conditions (non-referential condition: HFA: $Z=-2.840, p=.005$, SLI: $Z=-2.811$, $p=.005$; referential condition: HFA: $Z=-2.781, p=.005$, SLI: $Z=-2.672, p=.008$ ). Corroborating evidence for this result in SLI comes from the studies by Polite et al. (2011) and Chondrogianni \& Marinis (2015) who also found overuse of the indefinite article in SLI.

\subsection{Individual results}

The box plots in Figure 9 and 10 show that there is quite some individual variation in the pathological (HFA and SLI) groups, whereas the TD group is much more stable.

Therefore, we also examined the individual results of the pathological groups, and divided all impaired children (HFA and SLI) into "passers" (+) and "failers" $(-)$ for both experiments. For MC, participants received a 'pass' (+) if they have an accuracy score of at least $78 \%$ (18 or more correct out of 23 test items), otherwise they received a 'fail'. For AC, participants were assigned a pass (+) if they had one 


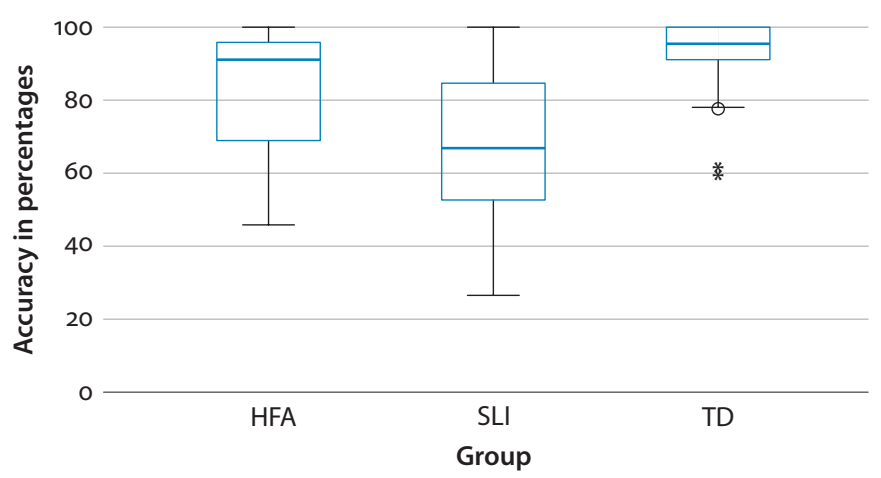

Figure 9. MC: Boxplots of accuracy per group

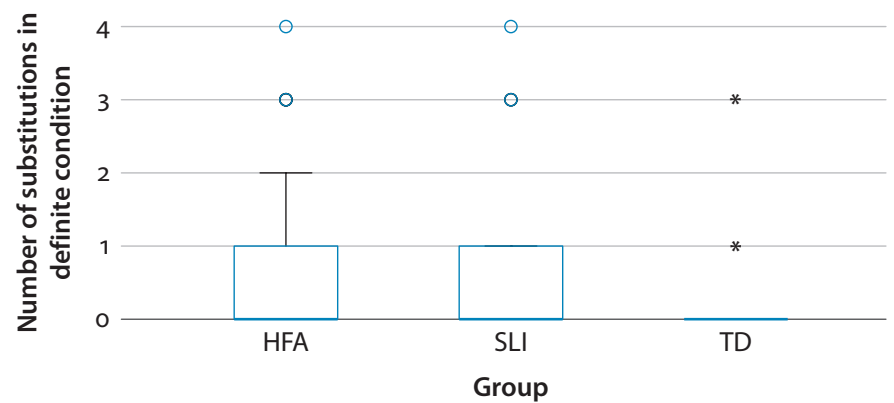

Figure 10. AC: Boxplots of number of substitutions in definite condition

substitution or less ( 5 or more out of 6 correct, or at least $83 \%$ ), and a fail (-) if they had more than one substitution. These cut-off points are based on the scores of the TD control group on the same tests. The pass/fail analysis generated four subgroups: + MC/-AC; $-\mathrm{MC} /+\mathrm{AC}$; $-\mathrm{MC} /-\mathrm{AC}$; $\mathrm{MC} /+\mathrm{AC}$, as presented in Table 1 .

Table 1. Four subgroups based on MC and AC performance: for MC the accuracy score for the combined mass/count conditions is given, for AC the amount of substitutions in the definite condition.

\begin{tabular}{llrll}
\hline Subgroup & Group & $\mathrm{N}$ & $\mathrm{MC}(\mathrm{SD})$ & $\mathrm{AC}(\mathrm{SD})$ \\
\hline$+\mathrm{MC} /-\mathrm{AC}$ & HFA & 4 & $0.96(0.08)$ & $3.25(0.5)$ \\
& SLI & 1 & $0.87(0)$ & $3(0)$ \\
$-\mathrm{MC} /+\mathrm{AC}$ & $\mathrm{HFA}$ & 7 & $0.58(0.11)$ & $0.14(0.38)$ \\
& SLI & 13 & $0.54(0.12)$ & $0.15(0.38)$ \\
$-\mathrm{MC} /-\mathrm{AC}$ & HFA & 2 & $0.61(0.17)$ & $2.5(0.71)$ \\
& SLI & 3 & $0.65(0.05)$ & $3.33(0.58)$ \\
$+\mathrm{MC} /+\mathrm{AC}$ & HFA & 14 & $0.94(0.06)$ & $0.21(0.43)$ \\
& SLI & 10 & $0.88(0.8)$ & $0.40(0.52)$ \\
\hline
\end{tabular}


Table 1 shows that there is a subgroup within the SLI group that shows a pattern opposite to a subgroup in the HFA group and vice versa: in the $+\mathrm{MC} /-\mathrm{AC}$ subgroup (or the - according to our hypothesis - 'typical HFA' group), there are 4 (out of 27) children with HFA, and in the $-\mathrm{MC} /+\mathrm{AC}$ subgroup (or the 'typical SLI' group), there are 13 children (out of 27) with SLI. These results reveal a double dissociation: we find an SLI subgroup that has impaired grammatical skills, but intact pragmatic skills, and a HFA subgroup that has impaired pragmatic skills, but intact grammatical skills. This suggests that grammar and pragmatics can be impaired independently of each other, and therefore provides evidence for our first hypothesis that grammar and pragmatics are two distinct components of language, which can be selectively impaired.

Regarding our second hypothesis, our group results show that, despite the similarity of the SLI and HFA groups in terms of pragmatic performance (article choice), the groups differ in terms of grammar (mass-count distinction): the SLI group performs significantly worse than their TD age-mates, while the HFA group is TD-like in this respect. The SLI and HFA groups thus show different linguistic profiles, suggesting different underlying causes for their linguistic behaviour, and possibly also for their respective pragmatic deficits.

Nevertheless, the attentive reader may have noticed from Table 1 that there seems to be one child within the SLI group who performs like the 'typical' HFA group $(+\mathrm{MC} /-\mathrm{AC})$ and a subgroup of 7 children within the HFA group who perform similarly to the 'typical' SLI group $(-\mathrm{MC} /+\mathrm{AC})$, suggesting that, after all, there may be some overlap between SLI and HFA. However, recall from the Methods section that the CELF-IV, a standardized language test of Dutch, was also administered, and that all children with SLI underperformed on this standardized language test. Comparing the CELF scores of the SLI-like children in the HFA group and the HFA-like children in the SLI group, we see a number of interesting differences between these groups, as illustrated in Table 2.

Table 2. CELF scores of four subgroups based on MC and AC performance

\begin{tabular}{llcc}
\hline Subgroup & Group & $\mathrm{N}$ & CELF (SD) \\
\hline$+\mathrm{MC} /-\mathrm{AC}$ & HFA & 4 & $89.9(9.3)$ \\
& SLI & 1 & 9.1 \\
$-\mathrm{MC} /+\mathrm{AC}$ & HFA & 7 & $18.2(12.8)$ \\
& SLI & 13 & $5.1(6.1)$ \\
$-\mathrm{MC} /-\mathrm{AC}$ & HFA & 2 & $62.8(10.6)$ \\
& SLI & 3 & $7.7(10.0)$ \\
$+\mathrm{MC} /+\mathrm{AC}$ & HFA & 14 & $63.8(22.5)$ \\
& SLI & 10 & $12.9(6.7)$ \\
\hline
\end{tabular}


In the $+\mathrm{MC} /-\mathrm{AC}$ group the one child with SLI has a much lower CELF score than the children with HFA in this group. ${ }^{3}$ In line with this, in the $-\mathrm{MC} /+\mathrm{AC}$ group the 7 children with HFA have a significantly higher mean CELF score than the 13 children with SLI (CELF: $\mathrm{U}=13, p=.009$ ).

Although the results do show that there is a subgroup of HFA that is clearly grammatically impaired (they fail on mass-count and the CELF score is below the norm), this impairment seems less severe than the grammatical impairment in SLI. ${ }^{4}$ Furthermore, the 4 SLI AC failers suggest that children with SLI can have an additional pragmatic impairment, i.e., PLI (Bishop 2000; Gibson et al. 2013). Yet, it is not clear whether this pragmatic impairment is caused by the same underlying factors as the pragmatic impairment in the children with HFA, considering their different profiles in terms of Mass-Count and CELF.

In summary, taking the results on Mass-Count, Article Choice, and CELF together, HFA and SLI appear to have quite distinct linguistic profiles, leaving little support for the hypothesis that HFA and SLI are part of the same continuum.

\section{Conclusion}

In this study, we examined the mass-count distinction in flexible nouns (for which morphosyntactic knowledge is crucial) and the choice for a definite or indefinite article (based on pragmatic principles) in children with High Functioning Autism (HFA) and in children with SLI.

Although both groups make substantial errors in article choice (pragmatics), they differ in terms of mass-count (grammar): the SLI group is weak, while the HFA group is not. This suggests that the SLI and HFA linguistic profiles do not resemble each other. This is further confirmed by the results on the CELF-IV. Thus, our data show little evidence for the hypothesis that SLI and HFA are part of the same continuum.

Our results further show that pragmatics can be impaired independently from grammar (in HFA) and vice versa (in SLI), providing evidence for a modular view of grammar and pragmatics.

3. Due to the small sample size ( $\mathrm{N}=1$ in the SLI subgroup), statistical analysis is not meaningful here.

4. Moreover, comparison of the MC and the CELF scores shows that despite low CELF performance, sensitivity to the nominal plural morpheme can still be in tact: there are 11 children with SLI who have a very low CELF score, but are still MC passers. This suggests that a problem with plural morpheme recognition/processing implies low CELF performance, but not vice versa. 


\section{References}

American Psychiatric Association. 2000. Diagnostic and Statistical Manual of Mental Disorders (4th ed.). Washington, DC: American Psychiatric Association.

Barner, D. \& J. Snedeker. 2005. "Quantity judgments and individuation: Evidence that mass nouns count”. Cognition 97.41-66. DOI: 10.1016/j.cognition.2004.06.009

Baron-Cohen, S. 1988. "Social and pragmatic deficits in autism: Cognitive or affective?" Journal of Autism and Developmental Disorders 18:3.379-402. DOI: 10.1007/BF02212194

De Belder, Marijke. 2011. Roots and Affixes. Eliminating Lexical Categories from Syntax. LOT Publications, Utrecht.

Bishop, Dorothy. 2000. "Pragmatic language impairment: A correlate of SLI, a distinct subgroup, or part of the autistic continuum". Speech and language impairments in children: Causes, characteristics, intervention and outcome ed. by D. Bishop and L. Leonard, 99-113. Hove: Psychology Press.

Borer, Hagit. 2005. In Name Only: Structuring Sense vol. I. Oxford University Press.

DOI: 10.1093/acprof:oso/9780199263905.001.0001

Chondrogianni, V., \& T. Marinis. 2015. "Production of definite and indefinite articles in typically developing English-speaking children and children with SLI”. Lingua, 155.9-28.

DOI: 10.1016/j.lingua.2014.02.009

Fodor, Jerry A. 1983. The Modularity of Mind. Cambridge, MA: MIT Press.

Friedmann, Naama \& Rama Novogrodsky. 2008. "Subtypes of SLI: SySLI, PhoSLI, LeSLI, and PraSLI”. Language Acquisition and Development ed. by A. Gavarró \& M. J. Freitas, 205-217. Newcastle, UK: Cambridge Scholars Press/CSP.

Friedmann, N., \& R. Novogrodsky. 2011. "Which questions are most difficult to understand? The comprehension of Wh questions in three subtypes of SLI." Lingua 121.367-382.

DOI: 10.1016/j.lingua.2010.10.004

Frith, U. 1989. "Autism: Explaining the enigma”. British Journal of Developmental Psychology 3.465-468.

Froud, K., \& H. van der Lely. 2008. "The count-mass distinction in typically developing and grammatically specifically language impaired children: New evidence on the role of syntax and semantics". Journal of communication disorders 41:3.274-303.

DOI: $10.1016 /$ j.jcomdis.2007.11.001

Gibson, J., C. Adams, E. Lockton, \& J. Green. 2013. "Social communication disorder outside autism? A diagnostic classification approach to delineating pragmatic language impairment, high functioning autism and specific language impairment". Journal of Child Psychology and Psychiatry 54:11.1186-1197. DOI: 10.1111/jcpp.12079

Hacohen, Aviya \& Schaeffer, Jeannette. 2013. On the syntactic mass/count distinction in Hebrew child language - Language change? Paper presented at the Scandinavian Conference on Linguistics, Workshop on syntactic issues in Language Acquisition.

Hawkins, J. A. 1991. "On (in)definite articles: Implicatures and (un)grammaticality prediction". Journal of Linguistics 27.405-442. DOI: 10.1017/S0022226700012731

Heim, Irene. 1982. The semantics of definite and indefinite NPs. Ph.D. Dissertation, University of Massachusetts, Amherst: GLSA.

Horn, Laurence R. 2006. "Toward a Fregean pragmatics: Voraussetzung, Nebengedanke, Andeutung." Explorations in Pragmatics: Linguistic, Cognitive, and Intercultural Aspects, ed. by L. R. Horn \& I. Kecskes, 39-69. Berlin: Mouton. 
Van Hout, A., K. Harrigan, \& J. de Villiers. 2010. "Asymmetries in the acquisition of definite and indefinite NPs”. Lingua 120(8). 1973-1990. DOI: 10.1016/j.lingua.2010.02.006

Karmiloff-Smith, Annette. 1979. A Functional Approach to Child Language. Cambridge: Cambridge University Press.

Kjelgaard, M. M. \& Tager-Flusberg, H. 2001. "An investigation of language impairment in autism: Implications for genetic subgroups". Language and cognitive processes 16:2-3.287-308. DOI: $10.1080 / 01690960042000058$

Van der Lely, H. 1998. "SLI in children: Movement, economy and deficits in the computationalsyntactic system”. Language Acquisition 7.161-192. DOI: 10.1207/s15327817la0702-4_4

Maratsos, Michael P. 1976. The use of definite and indefinite reference in young children: An experimental study of semantic acquisition. Cambridge: Cambridge University Press.

Noveck, I. 2001. "When children are more logical than adults: Experimental investigations of scalar implicature”. Cognition 78:2.165-188. DOI: 10.1016/S0010-0277(00)00114-1

Papafragou, A. 2006. "From scalar semantics to implicature: Children's interpretation of aspectuals". Journal of Child Language 33.721-757. DOI: 10.1017/S0305000906007550

Papafragou, A, \& J. Musolino. 2003. "Scalar implicatures: experiments at the semantics pragmatics interface”. Cognition 86:3.253-282. DOI: 10.1016/S0010-0277(02)00179-8

Perovic, A., N. Modyanova \& K. Wexler. 2013. "Comprehension of reflexive and personal pronouns in children with autism: A syntactic or pragmatic deficit?" Applied Psycholinguistics 34:4.813-835. DOI: 10.1017/S0142716412000033

Polite, E. J., L. B. Leonard \& F. D. Roberts. 2011. "The use of definite and in-definite articles by children with specific language impairment." International Journal of Speech-Language Pathology 13.291-300. DOI: 10.3109/17549507.2011.558116

Pouscoulous, N., I. A. Noveck, G. Politzer \& A. Bastide. 2007. "A developmental investigation of processing costs in implicature production”. Language Acquisition 14:4.347-375. DOI: $10.1080 / 10489220701600457$

Rumelhart, David \& James L. McClelland. 1987. Parallel Distributed Processing. Cambridge, MA: MIT Press.

Schaeffer, J. \& L. Matthewson. 2005. "Grammar and pragmatics in the acquisition of article systems”. Natural Language \& Linguistic Theory 23:1.53-101. DOI: 10.1007/s11049-004-5540-1

Semel, Eleanor M., Elisabeth H. Wiig, Wayne A. Secord \& Willem Kort. 2008. CELF 4 NL: Clinical evaluation of language fundamentals: Nederlandse versie. Pearson.

Stalnaker, Robert. 1974. "Pragmatic presuppositions". Semantics and Philosophy ed. by M. K. Munitz \& P. Unger, 197-214. New York: New York University Press.

Stalnaker, Robert. 1978. “Assertion”. Syntax and Semantics 9: Pragmatics ed. by P. Cole, 313-332. New York: Academic Press.

Tager-Flusberg, Helen 1989. "A psycholinguistic perspective on language development in the autistic child". Autism: Nature, diagnosis, and treatment ed. by G. Dawson, 92-115. New York: Guilford press. 
Authors' addresses

Ava Creemers

Department of Linguistics

University of Pennsylvania

619 Williams Hall

255 S 36th Street, Philadelphia

PA 19104-6305 USA

Creemers@sas.upenn.edu
Jeannette Schaeffer

Department of Literary Studies and

Linguistics

University of Amsterdam

Spuistraat 210

1012 VT Amsterdam

The Netherlands

J.C.Schaeffer@uva.nl 